\title{
Outcomes of endoscopic sleeve gastroplasty; how does it compare to laparoscopic sleeve gastrectomy? A systematic review and meta-analysis
}

\section{(ㄷ)(우우}

Authors

Babu P. Mohan ${ }^{*}$, , Ravishankar Asokkumar ${ }^{*}$, , Shahab R. Khan³, Rajesh Kotagiri', Gurusravanan Kutti Sridharan', Saurabh Chandan ${ }^{4}$, Naveen PG. Ravikumar ${ }^{5}$, Suresh Ponnada ${ }^{6}$, Mahendran Jayaraj ${ }^{7}$, Douglas G. Adler ${ }^{8}$

Institutions

1 Internal Medicine, University of Arizona, Banner University Medical Center, Tucson, Arizona, United States

2 Department of Gastroenterology and Hepatology, Singapore General Hospital, Singapore

3 Section of Gastroenterology, Rush University Medical Center, Chicago, Illinois, United States

4 Gastroenterology and Hepatology, University of Nebraska Medical Center, Omaha, Nebraska, United States

5 Internal Medicine, University at Buffalo, Buffalo General Hospital, Buffalo, New York, United States

6 Internal Medicine, Carilion Roanoke Memorial Hospital, Roanoke, Virginia, United States

7 Department of Gastroenterology and Hepatology, University of Nevada, Las Vegas, Nevada, United States

8 Division of Gastroenterology and Hepatology, University of Utah School of Medicine, Salt Lake City, Utah, United States

submitted 12.9.2019

accepted after revision $\quad 23.1 .2020$

Bibliography

DOI https://doi.org/10.1055/a-1120-8350 |

Endoscopy International Open 2020; 08: E558-E565

(c) Georg Thieme Verlag KG Stuttgart · New York eISSN 2196-9736

Corresponding author

Douglas G. Adler MD, FACG, AGAF, FASGE, Professor of Medicine, Director of Therapeutic Endoscopy, Director, GI fellowship Program, Gastroenterology and Hepatology, University of Utah School of Medicine, Huntsman Cancer Center, 30N 1900E 4R118, Salt Lake City, Utah 84132

Fax: +1-801-581-8007

Douglas.adler@hsc.utah.edu $\circledast$ Supplementary materials

Online content viewable at:

https://doi.org/10.1055/a-1120-8350

\section{ABSTRACT}

Background and study aims Endoscopic sleeve gastroplasty (ESG) is a novel moderately invasive technique in endo-bariatrics as compared to laparoscopic sleeve gastrectomy (LSG). Data is limited as to its efficacy and safety. Methods We searched multiple databases from inception through August 2019 to identify studies that reported on ESG in the treatment of obesity. Our goals were to calculate the pooled rates of total weight loss (\%TWL), excess weight loss (\%EWL), and body mass index (BMI) at 1 month, 6 months, and 12 months with ESG. We included studies that reported on LSG, in a similar time frame as ESG, and compared the 12-month outcomes.

Results From eight studies on ESG (1815 patients), the pooled rates of \%TWL at 1 month, 6 months, and 12 months were 8.7 (7.2-10.2), $15.3(14.1-16.6)$ and 17.1 (15.1$19.1)$, respectively. The pooled rates of \%EWL at 1 month, 6 months, and 12 months were 31.7 (29.3-34.1), 59.4 (57-61.8) and 63 (51.3-74.6), respectively. The pooled rates of BMl at $1 \mathrm{~m}, 6 \mathrm{~m}$, and $12 \mathrm{~m}$ were $32.6(31-34.3)$, $30.4(29-31.8)$ and $30\left(27.7-32.3, \mathrm{I}^{2}=97\right)$, respectively. At 12 months, the pooled \%TWL, \%EWL and BMI with LSG (7 studies, 2179 patients) were 30.5 (27.4-33.5), 69.3 (60.1-78.4) and $29.3(27.1-31.4)$ respectively. On comparison analysis, \%TWL with LSG was superior to ESG ( $P=$ 0.001). \%EWL and BMI were comparable. All adverse events, bleeding and gastro-esophageal reflux disease were significantly lower with ESG when compared to LSG. Conclusion ESG demonstrates acceptable weight loss parameters and seems to have a better safety profile when compared to LSG.

\footnotetext{
* These authors contributed equally.
} 


\section{Introduction}

Obesity is a global pandemic affecting more than 600 million people worldwide and is associated with multiple serious comorbidities [1]. Lifestyle and medical therapy alone fail to achieve sustained long-term weight loss in a large proportion of patients [2,3]. Despite progress in understanding the complex mechanisms in obesity, bariatric surgery remains the only current treatment option that demonstrates long-term effectiveness [4,5]. Procedures like gastric bypass, sleeve gastrectomy, gastric banding, and biliopancreatic bypass function creating different anatomical reconstructions to effect weight loss via malabsorption, gastric lumen size restriction, or both [6].

Among the available surgical techniques, laparoscopic sleeve gastrectomy (LSG) remains the most popular option owing to its operative simplicity, shorter procedure time, and better safety profile as compared to gastric bypass or other malabsorptive surgery [7]. A multicenter randomized controlled trial showed no significant difference in excess body mass index (BMI) loss between LSG and laparascopic Roux-en-Y gastric bypass (RYGB) at 5 years of follow-up [8]. Despite this, there is a wide gap in the percentage of patients seeking surgical treatment for obesity as compared to the magnitude of the disease. Only $1 \%$ undergo surgery. Potential reasons for this include fear of complications, irreversibility of the procedure, cost, and lack of widespread accessibility to surgery [9].

Endoscopic sleeve gastroplasty (ESG) is a novel, incisionless, minimally invasive procedure that is analogous to LSG and is appropriate for patients who do not want bariatric surgery. In ESG, a tubular gastric sleeve is created using a transoral gastroplasty procedure that utilizes full-thickness endoscopic suturing system (OverStitch; Apollo Endosurgery, Austin, Texas, United States) creating a gastric volume that is approximately $70 \%$ less than the original. Currently, ESG outcomes have not been established in comparison to other options of bariatric surgery like LSG.

In this study, we performed a meta-analysis to evaluate the efficacy and safety of ESG in patients with moderate to severe obesity, and aimed to compare the 12-month outcomes with ESG to the 12-month outcomes with LSG.

\section{Methods}

\section{Search strategy}

We conducted a comprehensive search of several databases and conference proceedings including PubMed, EMBASE, Google-Scholar, SCOPUS, and Web of Science databases (earliest inception to August 2019). An experienced medical librarian using inputs from the study authors helped with the literature search. The search was restricted to studies in human subjects and published in English language in peer-reviewed journals. Two authors (BPM, RK) independently reviewed the title and abstract of studies identified in primary search and excluded studies that did not address the research question, based on pre-specified exclusion and inclusion criteria. The full texts of remaining articles were reviewed to determine whether it con- tained relevant information. Any discrepancy in article selection was resolved by consensus, and in discussion with a co-author. Search keywords are summarized in Appendix A, MOOSE checklist is provided as Appendix B and PRISMA checklist is provided as Appendix C.

The bibliographic section of the selected articles, as well as the systematic and narrative articles on the topic were manually searched for additional relevant articles. As this is a qualitative and quantitative synthesis of data already published, an IRB approval was not needed.

\section{Study selection}

In this meta-analysis, we included studies that evaluated clinical outcomes of ESG in patients with moderate to severe obesity. Studies were included irrespective of the study sample-size, inpatient/ outpatient setting, and geography as long as they provided data needed for the analysis. For the purpose of comparison, we included studies on LSG that were published from 2013 onwards. The reasons to limit the study search for LSG from 2013 are as follows: (1) the refined ESG procedure was first reported and published in 2013. Therefore, the authors decided to include studies evaluating LSG in a comparable time frame, and (2) majority of the studies on LSG report longterm clinical outcomes ( 3 years, 5 years, and 10 years). For the purposes of this study, we included LSG studies that reported 12-month outcomes to be able to compare with 12-month outcomes of ESG.

The following were our inclusion criteria: (1) studies on ESG; and (2) studies on LSG published 2013 onwards. Following were our exclusion criteria: (1) studies on LSG published until December 31, 2012; (2) studies on LSG published as abstracts; (3) studies on robot-assisted LSG; (4) studies that did not report outcomes on weight loss, in terms of total weight loss and/or excess weight loss and/or body mass index; (5) studies that did not report first 12 months' outcome data; (6) studies done exclusively in elderly and/or geriatric population (age $>60$ years); (7) studies done in a pediatric population (age $<18$ years); and (8) studies not published in English language.

In case of multiple publications from the same cohort and/or overlapping cohorts, data from the most recent and/or most appropriate comprehensive report were retained. Primary study authors were contacted via email for clarification with data and possible cohort overlap.

\section{Data abstraction and quality assessment}

Data on study-related outcomes in the individual studies were abstracted onto a standardized form by at least three authors (SRK, RK, GK), and two authors (BPM, SC) did the quality scoring independently. The Newcastle-Ottawa scale for cohort studies was used to assess the quality of studies [10]. This quality score consisted of 8 questions, the details of which are provided in Supplementary Table 1.

\section{Outcomes assessed}

1. Pooled rate of total weight loss (TWL\%) with ESG

2. Pooled rate of excess weight loss (EWL\%) with ESG, and

3. Pooled rate of body mass index (BMI) with ESG. 
The outcomes were measured at 1 month, 6 months, and 12 months after the index procedure.

Comparison analysis: The 12-month outcomes with ESG were compared to the 12-month outcomes of LSG.

Secondary analysis: Pooled rate of all adverse events (AEs): ESG vs LSG

Pooled rate of frequently encountered AE subtypes.

\section{Assessment methodology and definitions}

The collected data were matched between the groups (ESG and LSG) before statistical analysis. This model of comparison is comparable to a retrospective case-control study with matched groups and studies with similar comparison by meta-analysis have been published before [11-15]. Procedure-related complications were considered as AEs if the patient was admitted and/or taken for surgery to manage pain, bleeding, and operative site leak.

\section{Statistical analysis}

We used meta-analysis techniques to calculate the pooled estimates in each case following the methods suggested by DerSimonian and Laird using the random-effects model [16] When the incidence of an outcome was zero in a study, a continuity correction of 0.5 was added to the number of incident cases before statistical analysis [17] We assessed heterogeneity between study-specific estimates by using Cochran Q statistical test for heterogeneity, $95 \%$ prediction interval (PI), which deals with the dispersion of the effects [18-20] and the I $\mathrm{I}^{2}$ statistics $[21,22]$ In this, values $<30 \%, 30 \%$ to $60 \%, 61 \%$ to $75 \%$, and $>75 \%$ were suggestive of low, moderate, substantial, and considerable heterogeneity, respectively [23]. Publication bias was ascertained, qualitatively, by visual inspection of funnel plot and quantitatively, by the Egger test [24]. When publication bias was present, further statistics using the fail-Safe $\mathrm{N}$ test and Duval and Tweedie's "trim and fill" test was used to ascertain the impact of the bias [25]. Three levels of impact were reported based on the concordance between the reported results and the actual estimate if there was no bias. The impact was reported as minimal if both versions were estimated to be same, modest if effect size changed substantially but the final finding would still remain the same, and severe if basic final conclusion of the analysis is threatened by the bias [26]. Significance level was set to alpha $=0.05$ and all tests were two-sided.

All analyses were performed using Comprehensive Meta-Analysis (CMA) software, version 3 (BioStat, Englewood, New Jersey, United States).

\section{Results}

\section{Search results and population characteristics}

From an initial total of 9558 studies, 3270 records were screened and 39 full-length articles were assessed. Five ESG studies with overlapping study patients were removed after including the most comprehensive report [27-31]. The study by Kumar et al [32] was not included as it was the first in man trial focused on procedure development and reproducibility of ESG technique. Fifteen studies were included in the final analysis, of which 8 studies reported on the outcomes with ESG [33-40] and seven reported on the outcomes with LSG [41-47]. The schematic diagram of study selection is illustrated in Supplementary Fig. 1.

Baseline population characteristics were comparable between the ESG and LSG groups, except for the mean range of BMI. Mean range of BMI $\left(\mathrm{kg} / \mathrm{m}^{2}\right)$ was 33.3 to 38.9 in ESG cohort and 37.4 to 48 in LSG cohort. The mean and/or median age ranged from 30 years to 48 years, with predominantly females (75\%). The mean range of procedure time with ESG was 45 to 80 minutes and with LSG was 60 to 120 minutes. The hospital length of stay with ESG was 1-2 days and with LSG ranged from a mean of 5 days to 9 days. The sample characteristics are described in $\nabla$ Table 1 .

\section{Characteristics and quality of included studies}

Four of the seven ESG studies were prospective [34-36,39] whereas one that was a randomized controlled trial and all other LSG studies were retrospective [47]. Two ESG studies were from multi-center data $[37,40]$ and the rest were single center. None were population-based. Detailed assessment of study quality can be found in Supplementary Table 1. Overall, three studies $[37,39,40]$ were considered high quality and the rest were medium quality. There were no low-quality studies.

\section{Meta-analysis outcomes}

A total of 3994 patients were included in the analysis from 15 studies. Outcomes of ESG were analyzed from a total of eight studies (1815 patients) and outcomes of LSG were analyzed from seven studies (2179 patients).

\section{1-month, 6-month, \& 12 m meta-analysis outcomes with ESG}

The pooled rates of \%TWL at 1 month, 6 months, and 12 months were 8.7 (95\% Cl 7.2-10.2), 15.3 (95\% Cl 14.1-16.6), and 17.1 (95\% Cl 15.1-19.1), respectively. The pooled rates of \%EWL at 1 month, 6 months, and 12 months were $31.7(95 \% \mathrm{Cl}$ 29.3-34.1), 59.4 (95\% Cl 57-61.8), and 63 (95\% Cl 51.3-74.6), respectively. The pooled rates of BMI (mean BMI in $\mathrm{kg} / \mathrm{m}^{2}$ ) at 1 month, 6 months, and 12 months were 32.6 (95\% Cl 31-34.3), 30.4 (95\% Cl 29-31.8), and 30 (95\% Cl 27.7-32.3), respectively. (Forest plots: Supplementary Fig. 2-6)

\section{Comparison of ESG to LSG at 12-months}

At 12 months, the pooled rates of \%TWL, \%EWL, and BMI with LSG were 30.5 (95\% Cl 27.4-33.5), 69.3 (95\% Cl 60.1-78.4), and 29.3 (95\% Cl 27.1-31.4), respectively. LSG demonstrated statistically superior \%TWL when compared to ESG $(P=0.001)$, whereas \%EWL and BMI at 12-months with LSG and ESG were comparable ( $P=0.4$ and 0.65 , respectively). (Forest plots: Supplementary Fig. 4-6)

\section{Adverse events}

The pooled rate of all adverse events (AEs) with ESG was $2.9 \%$ (95\% Cl 1.8-4.4) and with LSG was $11.8 \%$ (95\% Cl 8.4-16.4), with $P=0.001$. The pooled rate of bleeding events with ESG was $1.1 \%(95 \% \mathrm{Cl} 0.7-1.8)$ and with LSG was $2.6 \%(95 \% \mathrm{Cl}$ 
- Table 1 Study and patient characteristics.

\begin{tabular}{|c|c|c|c|c|c|c|c|c|}
\hline Study & Design, location, time & $\begin{array}{l}\text { Inter- } \\
\text { vention }\end{array}$ & $\begin{array}{l}\text { Total } \\
\text { N }\end{array}$ & $\mathbf{M} / \mathbf{F}$ & $\begin{array}{l}\text { Age (years) } \\
\text { (mean or } \\
\text { median) }\end{array}$ & $\begin{array}{l}\text { BMI }\left(\mathrm{kg} / \mathrm{m}^{2}\right) \\
\text { (mean or } \\
\text { median) }\end{array}$ & $\begin{array}{l}\text { Procedure } \\
\text { time (min) }\end{array}$ & $\begin{array}{l}\text { Hospital } \\
\text { LOS (days) }\end{array}$ \\
\hline $\begin{array}{l}\text { Alqahtani, } \\
2019\end{array}$ & $\begin{array}{l}\text { Prospective, single center, } \\
\text { Saudi Arabia, Dec } 2016 \text { \& } \\
\text { Ongoing }\end{array}$ & ESG & 1000 & $103 / 897$ & $\begin{array}{l}34.4 \pm 9.5 \\
(18-60)\end{array}$ & $33.3 \pm 4.5$ & $82 \pm 20$ & $1-2$ \\
\hline $\begin{array}{l}\text { Barrichella, } \\
2019\end{array}$ & $\begin{array}{l}\text { Retrospective, multicenter, } \\
\text { Jul } 2017 \text { to Aug } 2018\end{array}$ & ESG & 193 & $45 / 148$ & $42.3(9.6)$ & $34.11(2.97)$ & $76(24)$ & \\
\hline $\begin{array}{l}\text { Bhandari, } \\
2019\end{array}$ & $\begin{array}{l}\text { Prospective, single center, } \\
\text { Mar } 2017 \text { to Oct 2018, India }\end{array}$ & ESG & 53 & $10 / 43$ & $\begin{array}{l}40.54 \\
(13.79)\end{array}$ & $34.78(5.2)$ & $\begin{array}{l}68.96 \\
(11.19)\end{array}$ & $2(1-3)$ \\
\hline Fayad, 2019 & $\begin{array}{l}\text { Retrospective, single center, } \\
\text { USA Dec } 2015 \text { to Oct } 2017\end{array}$ & ESG & 58 & $24 / 34$ & $48.2(11.8)$ & $41.5(8.2)$ & NR & NR \\
\hline $\begin{array}{l}\text { Lopez-Nava, } \\
2017\end{array}$ & $\begin{array}{l}\text { Prospective, single center, } \\
\text { Spain, May } 2013 \text { to Mar } 2016\end{array}$ & ESG & 154 & $46 / 108$ & $\begin{array}{l}44.9 \\
(23-69)\end{array}$ & $\begin{array}{l}38.3+-5.5 \\
(30-47)\end{array}$ & NR & 1 \\
\hline $\begin{array}{l}\text { Morales, } \\
2018\end{array}$ & $\begin{array}{l}\text { Retrospective, Spain, Jan } \\
2015 \text { to Feb } 2016\end{array}$ & ESG & 148 & $27 / 121$ & $41.53 \pm 10$ & $35.11 \pm 5.5$ & $45-60$ & $1-2$ \\
\hline $\begin{array}{l}\text { Sartoretto, } \\
2018\end{array}$ & $\begin{array}{l}\text { Retrospective, multicenter, } \\
\text { Australia, USA, Feb } 2016 \text { to } \\
\text { May } 2017\end{array}$ & ESG & 112 & $35 / 77$ & $45.1 \pm 11.7$ & $37.9 \pm 6.7$ & NR & 1 \\
\hline $\begin{array}{l}\text { Saumoy, } \\
2018\end{array}$ & $\begin{array}{l}\text { Prospective, single center, } \\
\text { USA, Aug } 2013 \text { to Dec } 2016\end{array}$ & ESG & 128 & $42 / 86$ & $\begin{array}{l}43.62 \pm \\
11.37\end{array}$ & $\begin{array}{l}38.92(6.95) \\
(30.02- \\
68.04)\end{array}$ & 82.5 & NR \\
\hline $\begin{array}{l}\text { Lemaitre, } \\
2016\end{array}$ & $\begin{array}{l}\text { Retrospective, single center, } \\
\text { France, Jan } 2008 \text { to Feb } 2013\end{array}$ & LSG & 494 & $127 / 367$ & $45.5 \pm 11.2$ & $\begin{array}{l}47.8 \pm 7.8 \\
(35.0-82.3)\end{array}$ & $\begin{array}{l}60 \text { ( } 40 \text { to } \\
90)\end{array}$ & $5(3$ to 21$)$ \\
\hline $\begin{array}{l}\text { El-Matbouly, } \\
2018\end{array}$ & $\begin{array}{l}\text { Retrospective, single center, } \\
\text { Qatar, Jan } 2011 \text { to Dec } 2014\end{array}$ & LSG & 91 & $46 / 45$ & $17 \pm 1.5$ & $48 \pm 7.5$ & $62.2 \pm 20.4$ & $3 \pm 1$ \\
\hline Wang, 2016 & $\begin{array}{l}\text { Restrospective, single center, } \\
\text { China, Jan } 2011 \text { to Feb } 2012\end{array}$ & LSG & 70 & $30 / 40$ & $30.33 \pm 8.61$ & 40.85 .9 & $\begin{array}{l}105.0+- \\
18.6\end{array}$ & NR \\
\hline $\begin{array}{l}\text { Golomb, } \\
2015\end{array}$ & $\begin{array}{l}\text { Retrospective, single center, } \\
\text { Israel, Apr 1, } 2006 \text { to Feb 28, } \\
2013\end{array}$ & LSG & 241 & $69 / 172$ & $42.9(12.5)$ & $41.9(6.7)$ & NR & NR \\
\hline $\begin{array}{l}\text { Alvarenga, } \\
2016\end{array}$ & $\begin{array}{l}\text { Retrospective, single center, } \\
\text { USA, Jan } 2005 \text { to Feb } 2014\end{array}$ & LSG & 1020 & $341 / 679$ & $38.4 \pm 16.5$ & $43.4 \pm 5.8$ & NR & $3.4 \pm 2.1$ \\
\hline $\begin{array}{l}\text { Zachariah, } \\
2013\end{array}$ & $\begin{array}{l}\text { Retrospective, single center, } \\
\text { Taiwan, Feb } 2007 \text { to Mar } \\
2012\end{array}$ & LSG & 228 & $83 / 145$ & $\begin{array}{l}34.68 \pm 10.1 \\
(18-62)\end{array}$ & $\begin{array}{l}37.42 \pm 4.75 \\
(32.08- \\
65.69)\end{array}$ & $\begin{array}{l}60.63 \pm \\
27.37(20- \\
170)\end{array}$ & $\begin{array}{l}1.08 \pm 1.01 \\
(1-7)\end{array}$ \\
\hline $\begin{array}{l}\text { Talebpour, } \\
2018\end{array}$ & $\begin{array}{l}\text { Randomized clinical trial, } \\
\text { Sina Hospital, Tehran Univer- } \\
\text { sity of Medical Sciences, } \\
\text { Tehran, Iran, } 2012 \text { to } 2015\end{array}$ & LSG & 35 & $6 / 29$ & $\begin{array}{l}38.60 \pm \\
10.27\end{array}$ & $44.60 \pm 3.50$ & NR & $\begin{array}{l}7.46 \pm 1.93 \\
\text { days }\end{array}$ \\
\hline
\end{tabular}

1.9-3.7), with $P=0.005$. The pooled rate of gastroesophageal reflux disease (GERD) with ESG was $0.4 \%(95 \% \mathrm{Cl} 0.1-1.1)$ and with LSG was $5.8 \%(95 \% \mathrm{Cl} 3.5-9.3)$, with $P=0.001$.

All bleeding events reported required transfusion and all GERD were based on patient reported symptoms. There were seven events of perigastric leak/collection. The pooled results are summarized in Table 2 . (Forest plots: Supplementary Fig. 7-9).

\section{Validation of meta-analysis results}

Sensitivity analysis

To assess whether any one study had a dominant effect on the meta-analysis, we excluded one study at a time and analyzed its effect on the main summary estimate. On this analysis, no single study significantly affected the outcome or the heterogeneity. 
- Table 2 Pooled results.

\begin{tabular}{|c|c|c|c|}
\hline ESG & $\% T W L$ & EWL & BMI \\
\hline \multicolumn{4}{|c|}{ Pooled rate $\left(95 \% \mathrm{Cl}, \mathrm{I}^{2}\right)$} \\
\hline At 1 month & $\begin{array}{l}8.7(7.2-10.2,85) \\
6 \text { studies } \\
\text { (PI: } 6 \text { to } 11)\end{array}$ & $\begin{array}{l}31.7(29.3-34.1,97) \\
4 \text { studies } \\
\text { (PI: } 0 \text { to } 60)\end{array}$ & $\begin{array}{l}32.6(31-34.3,98) \\
5 \text { studies } \\
\text { (PI: } 24 \text { to } 41)\end{array}$ \\
\hline At 6 months & $\begin{array}{l}15.3(14.1-16.6,94) \\
9 \text { studies } \\
\text { (PI } 10 \text { to } 21)\end{array}$ & $\begin{array}{l}59.4(57-61.8,94) \\
6 \text { studies } \\
\text { (PI: } 25 \text { to } 90)\end{array}$ & $\begin{array}{l}30.4(29-31.8,96) \\
7 \text { studies } \\
\text { (PI: } 24 \text { to } 37)\end{array}$ \\
\hline At 12 months & $\begin{array}{l}17.1(15.1-19.1,93) \\
6 \text { studies } \\
\text { (PI } 9 \text { to } 26)\end{array}$ & $\begin{array}{l}63(51.3-74.6,90) \\
4 \text { studies } \\
\text { (PI: } 0 \text { to } 124)\end{array}$ & $\begin{array}{l}30(27.7-32.3,97) \\
5 \text { studies } \\
\text { (PI: } 0 \text { to } 70)\end{array}$ \\
\hline \multicolumn{4}{|l|}{ LSG } \\
\hline At 12 months & $\begin{array}{l}30.5(27.4-33.5,97, P=0.001) \\
3 \text { studies }\end{array}$ & $\begin{array}{l}69.3,(60.1-78.4,99, P=0.4) \\
6 \text { studies }\end{array}$ & $\begin{array}{l}29.3(27.1-31.4,98, P=0.65) \\
6 \text { studies }\end{array}$ \\
\hline Adverse events & ESG & LSG & $P$ value \\
\hline All & $\begin{array}{l}2.9 \%(1.8-4.4,0) \\
8 \text { studies }\end{array}$ & $\begin{array}{l}11.8 \%(8.4-16.4,80) \\
5 \text { studies }\end{array}$ & 0.001 \\
\hline Bleeding & $\begin{array}{l}1.1 \%(0.7-1.8,11) \\
7 \text { studies }\end{array}$ & $\begin{array}{l}2.6 \%(1.9-3.7,0) \\
5 \text { studies }\end{array}$ & 0.005 \\
\hline GERD & $\begin{array}{l}0.4 \%(0.1-1.1,0) \\
7 \text { studies }\end{array}$ & $\begin{array}{l}5.8 \%(3.5-9.3,73) \\
5 \text { studies }\end{array}$ & 0.001 \\
\hline
\end{tabular}

\section{Heterogeneity}

We assessed dispersion of the calculated rates using the prediction interval $(\mathrm{PI})$ and $\mathrm{I}^{2}$ percentage values. The $\mathrm{PI}$ gives an idea of the range of the dispersion and $\mathrm{I}^{2}$ tell us what proportion of the dispersion is true vs chance [20]. The PI values are mentioned with the corresponding pooled rates in $>$ Table 2 . Narrow intervals were noted with \%TWL, 6-month and 12-month $\mathrm{BMI}$ results. Wide $\mathrm{PI}$ with high $\mathrm{I}^{2}$ values was noted with \%EWL results.

To assess potential reasons for heterogeneity, subgroup analysis was done based on prospective vs retrospective studies, and meta-regression analysis was done based on BMI (based on random effects, Knapp Hartung mean 2 -sided $P=0.11$ ). This did not explain the reasons for the observed heterogeneity.

\section{Publication bias}

Based on visual inspection of the funnel plot as well as quantitative measurement that used the Egger regression test, there was evidence of publication bias (Supplementary Fig. 10, Eggers two-tailed $P=0.04$ ). Further statistics using the fail-Safe $N$ test and Duval and Tweedie's "trim and fill" test revealed that the impact of the possible publication bias appeared to be minimal and would not change the calculated estimate or the conclusion of this meta-analysis.

\section{Discussion}

Our study confirms that ESG achieves weight loss in patients with obesity over a 12-month period. ESG demonstrated an excellent safety profile when compared to LSG. This study is the most updated meta-analysis and is the first meta-analysis reporting on the pooled rates of anthropometric parameters in patients with obesity undergoing ESG with a non-causal subgroup comparison to LSG.

We chose to report the pooled \%TWL and \%EWL as these were commonly reported in the included studies and the bariatric literature. \%TWL is more preferred and gives more accurate measure than \%EWL. \%EWL is dependent on ideal body weight, which is an arbitrary measure based on metropolitan weight scale, and the pre-operative BMI. \%TWL is less influenced by, and is independent of, initial BMI [4]. Based on our analysis, the \%TWL was about $9 \%$ at 1 month with ESG that increased to $15 \%$ at 6 months and further increased to $17 \%$ at 12 months. The \%EWL with ESG was $32 \%$ at 1 month that progressed to $59 \%$ at 6 months and to $63 \%$ at 12 months. BMI followed a decreasing trend with ESG from 1 month $\left(33 \mathrm{~kg} / \mathrm{m}^{2}\right)$ to 6 -months $\left(30 \mathrm{~kg} / \mathrm{m}^{2}\right)$. Based on our findings, BMI with ESG was noted to plateau between 6 -months $\left(30 \mathrm{~kg} / \mathrm{m}^{2}\right)$ and 12 months $\left(30 \mathrm{~kg} / \mathrm{m}^{2}\right)$.

We compared the 12-month outcomes data between ESG and LSG by means of sub-group comparison that should be considered non-causal. At 12 months, \%TWL with ESG was inferior to LSG ( $17 \%$ vs $30.5 \%, P=0.001)$. Whereas, \%EWL $(63 \%$ 
vs $69 \%, P=0.4$ ) and change in BMI at 12 -months (30 vs $29, P=$ $0.65)$ were comparable between ESG and LSG. The mean range of $\mathrm{BMI}$ in LSG cohort tended to be higher than the mean range of $\mathrm{BMI}$ in ESG cohort, as the current BMI inclusion criteria is different for ESG $(B M I<40)$ and LSG $(B M I>40$, or $\mathrm{BMI}>35$ with medical comorbidities). It is important to note that, in order to have a fair comparison, we only included those LSG studies that were published 2013 onwards and reported 12-month outcomes. Literature published on LSG is far too many and majority of them report 3-year, 5-year and sometimes 10-year outcome data. Such studies were obviously not included in this analysis as such long-term follow up data on ESG is currently lacking.

Our analysis of overall AEs demonstrated a superior safety profile for ESG when compared to LSG ( $3 \%$ vs $12 \%, P=0.001$ ), recognizing that ESG is a new procedure with fewer physicians performing it to date i.e. expert endoscopists and not general endoscopists. In addition to the better safety profile, the mean range of procedure time with ESG was shorter when compared to LSG (45 to 80 minutes with ESG vs 60 to 120 minutes with LSG), as was the mean range of hospital length of stay (1-2 days with ESG vs 5-9 days with LSG). In our analysis of the AE subtypes with both procedures, the most frequently reported ones were bleeding and GERD. The pooled event of bleeding was fewer with ESG as compared to LSG $(1.1 \%$ vs $2.6 \%, P=$ $0.005)$. GERD is a well-established AE of LSG and expert consensus considers the presence of GERD to be a contraindication to LSG [48] ESG, unlike LSG, is not prone to predisposing patients to GERD and our analysis establishes this fact. The pooled GERD rate was significantly lower with ESG when compared to LSG (0.4\% vs $6 \%, P=0.001)$.

How does our study compare to other published works in literature? The case-matched retrospective study by Fayad et al. compared ESG and LSG [30]. At 6 months, ESG demonstrated significantly lower \%TWL when compared to LSG (17\% vs $24 \%$, $P<0.01)$ and the overall adverse events were lower with ESG than LSG ( $5 \%$ vs $17 \%, P<0.05$ ). The findings of the study by Fayad et al. were consistent with an earlier study by Novikov et al, who demonstrated comparable \%TWL at 12 months for BMI $<40 \mathrm{~kg} / \mathrm{m}^{2}$ between ESG and LSG [49]. This study differs in the reported \%TWL outcome between ESG and LSG at 12 months. At the time this study was under review, two other meta-analyses were published describing the pooled rates of ESG [50,51]. Our results are on-par with their reported pooled rates, however, our study is unique owing to the fact that we have put the 12-month pooled outcomes of ESG in perspective to the 12-months' pooled outcomes of LSG, and in addition this study is more up-to-date with 1815 patients.

The strengths of this review are as follows: systematic literature search with well-defined inclusion criteria, careful exclusion of redundant studies, inclusion of good quality studies with detailed extraction of data, rigorous evaluation of study quality, updated large number of patients, and statistics to establish and/or refute the validity of the results of our meta-analysis. With a total of 1815 patients in ESG group and 2179 patients in LSG group, this study is the largest in literature thus far.
There are limitations to this study, most of which are inherent to any meta-analysis. The included studies were not entirely representative of the general population and community practice, with most studies being performed in tertiary-care referral centers. Our analysis had studies that were retrospective in nature contributing to selection bias. We were not able to analyze our results based on the presence of comorbidities and were not able to assess the effects of ESG on these comorbidities. In addition, we were not able to assess predictors of ESG success and/or failure.

Our 12-month data comparing ESG outcomes to LSG are non-causal. We do not deny the possibility of additional confounding factors between ESG and LSG cohorts apart from BMI. We chose to include only those LSG studies that were done in a similar time frame to ESG and only those that had reported 12-month outcomes. The majority of LSG studies in literature report long-term patient outcomes in terms of 3 years, 5 years and 10 years, however, we do not have similar ESG studies with such long-term data. The presence of heterogeneity and wide prediction intervals were not statistically explainable. Nevertheless, our study is the best available estimate in literature thus far with respect to ESG's performance to LSG at 12 months. Future well-conducted studies are warranted comparing ESG to other conventional bariatric interventions and assessing its long-term health outcomes along with cost-effectiveness.

\section{Conclusion}

In conclusion, our meta-analysis demonstrates that ESG appears to be an effective alternative option to LSG in the treatment of obesity. ESG is reversible, has a faster procedure time, shorter hospital length of stay, and better safety profile. Overall, LSG resulted in superior total weight loss compared to ESG at 12 months.

Competing interests

Dr. Adler is a consultant for Boston Scientific

\section{References}

[1] World Health Organization. World Health Organization obesity and overweight fact sheet. 2016

[2] Look ARG. Eight-year weight losses with an intensive lifestyle intervention: the look AHEAD study. Obesity (Silver Spring, Md) 2014; 22: 5-13

[3] Yanovski SZ, Yanovski JA. Long-term drug treatment for obesity: a systematic and clinical review. JAMA 2014; 311: 74-86

[4] Corcelles R, Boules M, Froylich D et al. Total weight loss as the outcome measure of choice after Roux-en-Y gastric bypass. Obesity Surgery 2016; 26: 1794-1798

[5] Arterburn DE, Courcoulas AP. Bariatric surgery for obesity and metabolic conditions in adults. BMJ 2014; 349: g3961

[6] Fobi MA. Surgical treatment of obesity: a review. J Nat Med Assoc 2004; 96: 61-75 
[7] American Society for Metabolic and Bariatric Surgery. Estimate of bariatric surgery numbers, 2011-2017.

[8] Peterli R, Wolnerhanssen BK, Peters T et al. Effect of Laparoscopic sleeve gastrectomy vs laparoscopic Roux-en-Y gastric bypass on weight loss in patients with morbid obesity: the SM-BOSS randomized clinical trial. JAMA 2018; 319: 255-265

[9] Ponce J, DeMaria EJ, Nguyen NT et al. American Society for Metabolic and Bariatric Surgery estimation of bariatric surgery procedures in 2015 and surgeon workforce in the United States. Surg Obes Related Dis 2016; 12: 1637-1639

[10] Stang A. Critical evaluation of the Newcastle-Ottawa scale for the assessment of the quality of nonrandomized studies in meta-analyses. Europ J Epidemiol 2010; 25: 603-605

[11] Thompson SG, Pocock SJ. Can meta-analyses be trusted? Lancet 1991; 338: 1127-1130

[12] Mohan BP, Chandan S, Garg R et al. Lumen-apposing metal stents, fully covered self-expanding metal stents, and biodegradable stents in the management of benign of Gl strictures: a systematic review and meta-analysis. J Clin Gastroenterol 2019; 53: 560-573

[13] Mohan BP, Jayaraj M, Asokkumar R et al. Lumen apposing metal stents in drainage of pancreatic walled-off necrosis, are they any better than plastic stents? A systematic review and meta-analysis of studies published since the revised Atlanta classification of pancreatic fluid collections Endosc Ultrasound 2019; 8: 82-90

[14] Mohan BP, Shakhatreh M, Dugyala S et al. EUS versus percutaneous management of postoperative pancreatic fluid collection: A systematic review and meta-analysis. Endosc Ultrasound 2019; 8: 298309

[15] Mohan BP, Shakhatreh M, Garg R et al. Comparison of Franseen and fork-tip needles for EUS-guided fine-needle biopsy of solid mass lesions: A systematic review and meta-analysis. Endosc Ultrasound 2019; 8: 382-391

[16] DerSimonian R, Laird N. Meta-analysis in clinical trials. Contr Clin Trials 1986; 7: 177-188

[17] Sutton AJ, Abrams KR, Jones DR et al. Methods for meta-analysis in medical research. New York: John Wiley \& Sons Ltd; 2000

[18] Higgins J, Thompson SG, Spiegelhalter DJ. A re-evaluation of randomeffects meta-analysis. Journal of the Royal Statistical Society: Series A (Statistics in Society) 2009; 172: 137-159

[19] Riley RD, Higgins JP, Deeks JJ. Interpretation of random effects metaanalyses. BMJ 2011; 342: d549

[20] Mohan BP, Adler DG. Heterogeneity in systematic review and metaanalysis: how to read between the numbers. Gastrointest Endosc 2019; 89: 902-903

[21] Kanwal F, White D. Systematic Reviews and Meta-analyses; in Clinical Gastroenterology and Hepatology. Clin Gastroenterol Hepatol 2012; 10: $1184-1186$

[22] Higgins JP, Thompson SG, Deeks JJ et al. Measuring inconsistency in meta-analyses. BMJ 2003; 327: 557

[23] Guyatt GH, Oxman AD, Kunz R et al. GRADE guidelines: 7. Rating the quality of evidence; inconsistency. J Clin Epidemiol 2011; 64: 12941302

[24] Easterbrook PJ, Gopalan R, Berlin JA et al. Publication bias in clinical research. Lancet 1991; 337: 867-872

[25] Duval S, Tweedie R. Trim and fill: A simple funnel-plot-based method of testing and adjusting for publication bias in meta-analysis. Biometrics 2000; 56: 455-463

[26] Rothstein HR, Sutton AJ, Borenstein M. Publication bias in meta-analysis: Prevention, assessment and adjustments. New York: John Wiley \& Sons; 2006

[27] Abu Dayyeh BK, Acosta A, Camilleri M et al. Endoscopic sleeve gastroplasty alters gastric physiology and induces loss of body weight in obese individuals. Clin Gastroenterol Hepatol 2017; 15: 37-43.e1
[28] Hill C, El Zein M, Agnihotri A et al. Endoscopic sleeve gastroplasty: the learning curve. Endosc Int Open 2017; 5: E900-E904

[29] Lopez-Nava G, Sharaiha RZ, Vargas EJ et al. Endoscopic Sleeve gastroplasty for obesity: a multicenter study of 248 patients with 24 months follow-up. Obesity Surg 2017; 27: 2649-2655

[30] Fayad L, Adam A, Schweitzer M et al. Endoscopic sleeve gastroplasty versus laparoscopic sleeve gastrectomy: a case-matched study. Gastrointest Endosc 2019; 89: 782-788

[31] Sharaiha RZ, Kumta NA, Saumoy M et al. Endoscopic sleeve gastroplasty significantly reduces body mass index and metabolic complications in obese patients. Clin Gastroenterol Hepatol 2017; 15: 504510

[32] Kumar N, Abu Dayyeh BK, Lopez-Nava BG et al. Endoscopic sutured gastroplasty: procedure evolution from first-in-man cases through current technique. Surg Endosc 2018; 32: 2159-2164

[33] Fayad L, Cheskin LJ, Adam A et al. Endoscopic sleeve gastroplasty versus intragastric balloon insertion: efficacy, durability, and safety. Endoscopy 2019; 06: 06

[34] Alqahtani A, Al-Darwish A, Mahmoud AE et al. Short-term outcomes of endoscopic sleeve gastroplasty in 1000 consecutive patients. Gastrointest Endosc 2019; 89: 1132-1138

[35] Lopez-Nava G, Galvao MP, Bautista-Castano I et al. Endoscopic sleeve gastroplasty for obesity treatment: two years of experience. Brazn Arch Digest Surg 2017; 30: 18-20

[36] Saumoy M, Schneider Y, Zhou XK et al. A single-operator learning curve analysis for the endoscopic sleeve gastroplasty. Gastrointest Endosc 2018; 87: 442-447

[37] Sartoretto A, Sui Z, Hill C et al. Endoscopic sleeve gastroplasty (ESG) Is a reproducible and effective endoscopic bariatric therapy suitable for widespread clinical adoption: a large, international multicenter study. Obesity Surg 2018; 28: 1812-1821

[38] Morales-Conde S, DelAgua IA, Moreno AB et al. Postoperative pain after conventional laparoscopic versus single-port sleeve gastrectomy: a prospective, randomized, controlled pilot study. Surgr Obes Rel Dis 2017; 13: 608-613

[39] Bhandari M, Jain S, Mathur W et al. Endoscopic sleeve gastroplasty is an effective and safe minimally invasive approach for treatment of obesity: first Indian experience. Digest Endosc 2019: doi:10.1111/ den. 13508

[40] Barrichello S, Hourneaux de Moura DT et al. Endoscopic sleeve gastroplasty in the management of overweight and obesity: an international multicenter study. Gastrointestl Endosc 2019; 90: 770-780

[41] Zachariah SK, Chang PC, Ooi AS et al. Laparoscopic sleeve gastrectomy for morbid obesity: 5 years experience from an Asian center of excellence. Obes Surg 2013; 23: 939-946

[42] Wang X, Chang XS, Gao L et al. Effectiveness of laparoscopic sleeve gastrectomy for weight loss and obesity-associated co-morbidities: a 3-year outcome from Mainland Chinese patients. Surg Obes Rel Dis 2016; $12: 1305-1311$

[43] Lemaître F, Léger $P$, Nedelcu $M$ et al. Laparoscopic sleeve gastrectomy in the South Pacific. Retrospective evaluation of 510 patients in a single institution. Int J Surg 2016; 30: 1-6

[44] Golomb I, Ben David M, Glass A et al. Long-term metabolic effects of laparoscopic sleeve gastrectomy. JAMA Surg 2015; 150: 1051-1057

[45] El-Matbouly MA, Khidir N, Touny HA et al. A 5-year follow-up study of laparoscopic sleeve gastrectomy among morbidly obese adolescents: does it improve body image and prevent and treat diabetes? Obes Surg 2018; 28: 513-519

[46] Alvarenga ES, Lo MenzoE, Szomstein S et al. Safety and efficacy of 1020 consecutive laparoscopic sleeve gastrectomies performed as a primary treatment modality for morbid obesity. A single-center experience from the metabolic and bariatric surgical accreditation 
quality and improvement program. Surg Endosc 2016; 30: $2673-$ 2678

[47] Talebpour M, Sadid D, Talebpour A et al. Comparison of short-term effectiveness and postoperative complications: laparoscopic gastric plication vs laparoscopic sleeve gastrectomy. Obes Surg 2018; 28 : 996-1001

[48] Gagner M, Hutchinson C, Rosenthal R. Fifth International Consensus Conference: current status of sleeve gastrectomy. Surg Obes Rel Dis 2016; 12: 750-756
[49] Novikov AA, Afaneh C, Saumoy M et al. Endoscopic sleeve gastroplasty, laparoscopic sleeve gastrectomy, and laparoscopic band for weight loss: how do they compare? J Gastrointest Surg 2018; 22: 267-273

[50] Hedjoudje A, Dayyeh BA, Cheskin L] et al. Efficacy and safety of endoscopic sleeve gastroplasty: a systematic review and meta-analysis. Clin Gastroenterol Hepatol 2019: doi:10.1016/j.cgh.2019.08.022

[51] Li P, Ma B, Gong S et al. Efficacy and safety of endoscopic sleeve gastroplasty for obesity patients: a meta-analysis. Surg Endosc 2020; 34: $1253-1260$ 